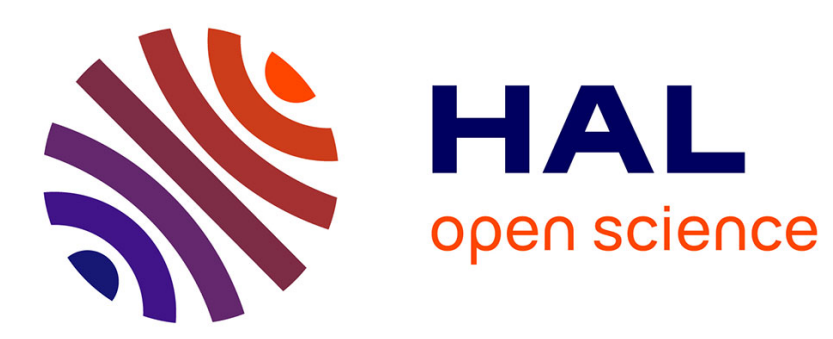

\title{
New meso-tetrafluorenylethynyl porphyrin platform
}

\author{
Xu Zhang, Christine O. Paul-Roth
}

\section{To cite this version:}

Xu Zhang, Christine O. Paul-Roth. New meso-tetrafluorenylethynyl porphyrin platform. Journal of Porphyrins and Phthalocyanines, 2019, Women in Porphyrin Science, 23 (1-2), pp.185-195. 10.1142/S1088424619500202 . hal-02086484

HAL Id: hal-02086484

https://hal-univ-rennes1.archives-ouvertes.fr/hal-02086484

Submitted on 11 Apr 2019

HAL is a multi-disciplinary open access archive for the deposit and dissemination of scientific research documents, whether they are published or not. The documents may come from teaching and research institutions in France or abroad, or from public or private research centers.
L'archive ouverte pluridisciplinaire HAL, est destinée au dépôt et à la diffusion de documents scientifiques de niveau recherche, publiés ou non, émanant des établissements d'enseignement et de recherche français ou étrangers, des laboratoires publics ou privés. 


\title{
manuscript, jpp180297 \\ for the Women in Porphyrin Science special issue
}

\author{
Graphical Abstract
}

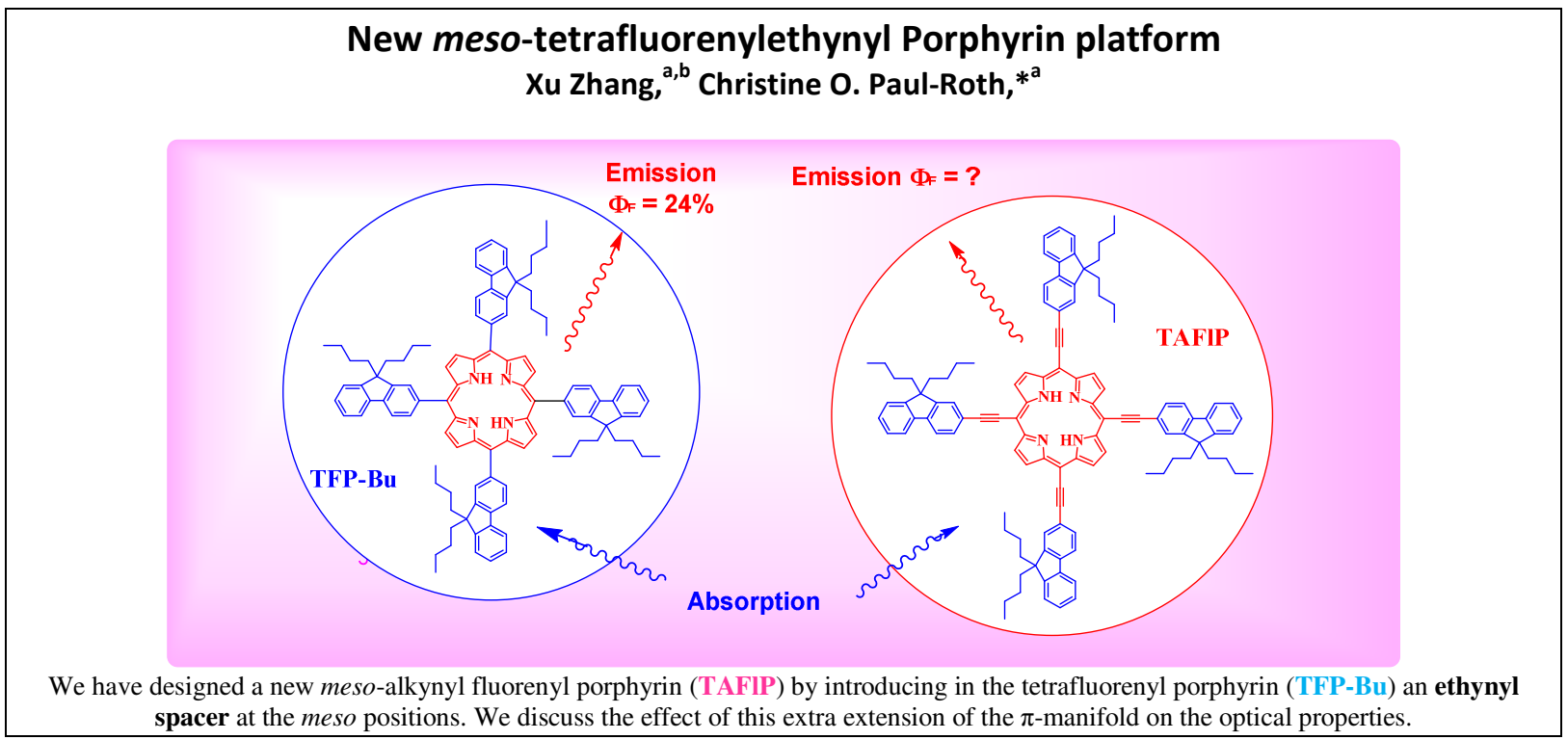




\title{
New meso-tetrafluorenylethynyl Porphyrin platform
}

\author{
Xu Zhang, ${ }^{a, b}$ Christine O. Paul-Roth, ${ }^{\text {a }}$ \\ "Dedicated to Dr Gérard Simonneaux for opening the door of the wonderful \\ world of Porphyrins" \\ ${ }^{a}$ Univ Rennes, INSA Rennes, CNRS, ISCR (Institut des Sciences Chimiques de Rennes) - UMR 6226, \\ F-35000 Rennes, France \\ ${ }^{b}$ Department of Chemistry, College of Chemistry and Chemical Engineering, Chifeng University, \\ Chifeng, P. R. China.
}

\begin{abstract}
To improve conjugation between a central porphyrin core and its peripheral fluorenyl antennae, we have introduced in the meso-tetrafluorenyl porphyrin (TFP-Bu) unit an ethynyl spacer at the meso positions. By this mean, we have synthesized and characterized a new meso-alkynyl fluorenyl porphyrin (TAFIP). We discuss the effect of this extra extension of the $\pi$-manifold on the optical properties. This enlarged porphyrin core, TAFIP, is foreseen as a key building block for the design of new dendrimers for theranostic applications. The constant improvement of porphyrin-based dendrimers featuring conjugated fluorenyl dendrons is recalled herein and demonstrates the important role of the central core structure in determining linear and nonlinear optical properties. Further improvement of these properties seems possible with TAFIP-like structures based on observations made for dendrimers recently obtained. This makes the exploration of new molecular architectures based on tetrafluorenyl ethynyl porphyrin appealing for PDT and related applications.
\end{abstract}

KEYWORDS: Porphyrin, fluorenyl, fluorescence, alkyne.

*Corresponding author: christine.paul@univ-rennes1.fr or christine.paul@insa-rennes.fr tel : (+33) (0) 223236372 fax: (+33) (0) 223236372

\section{INTRODUCTION}

There has been great interest in the synthesis of porphyrin systems because the peripheral substituent on the macrocyclic core can modulate the physical properties at will. Consequently, they present wide potential applications in different fields such as for instance light-harvesting, organic light emitting diodes (OLEDs) or switches. Porphyrin-based systems are largely present nowadays, in many applied developments encompassing by far the numerous bio-related studies in which these macrocycles were initially involved. ${ }^{\text {1a }}$ 
Stimulated by the fact that the unique photochemical properties of the porphyrin core can be fine-tuned by modification of the peripheral substituents, intense research in fields more related to photophysics and material sciences has been undertaken these last decades. Symmetrical A4 porphyrins type, substituted at the four meso positions, is particularly interesting because the molecules are easily accessible with good yields. Very appealing is also the synthetic expansion of such structures by introducing dendrons at these positions, and the modification of these dendrons for light harvesting. In this respect, many porphyrinbased dendrimers have been synthesized these last decades. Their light-harvesting properties could be optimized by connecting highly absorbing dendrons to the central porphyrin core, the former acting as energy donors to the second, overall behaving like an antenna system. ${ }^{\text {lb }}$ In particular, some porphyrins bearing pendent linear oligofluorene arms have been reported in this context, ${ }^{1 \mathrm{c}}$ and for such assemblies, Fréchet ${ }^{1 \mathrm{~d}}$ demonstrated that the antenna effect was facilitated in dendritic architectures versus linear ones. More recently, hyperbranched polymers containing porphyrin with fluorenyl arms have also been synthesized for light harvesting, ${ }^{1 \mathrm{e}}$ while the group of Okada and Kozaki investigated the use of series of multiporphyrin arrays in conjugated networks as light-harvesting antenna. ${ }^{1 \mathrm{f}}$ In this field, we also have recently reported efficient light-harvesting systems in which 5,10,15,20tetraphenylporphyrin (TPP) was linked, via flexible ether bridges, to fluorenyl donor

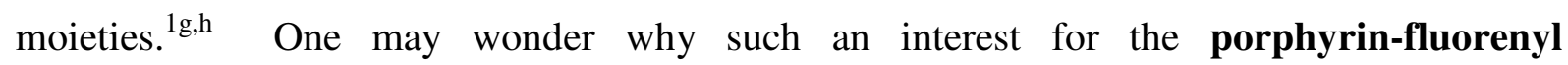
combinations. Actually, as we have discovered, in collaboration with J.A.G. Williams, 5,10,15,20-tetrafluorenylporphyrin (TFP) exhibits a high quantum yield (24\%), demonstrating the capacity of 2-fluorenyl units to strongly enhance the emission quantum yield of the porphyrin core. ${ }^{1 \mathrm{i}}$ Our aim was then to exploit further this capacity and a series of super porphyrins based on the small TPP-core was targeted. In the first family, the dendrons were linked via ether bridges to the central core. Four, eight and sixteen fluorenyl donor moieties were included in these dendrons. Then, we wondered about improving the lightharvesting mechanism by preserving some $\pi$-overlap between the peripheral fluorenyl arms and the central core. ${ }^{1 \mathrm{j}}$ Indeed, porphyrin-based dendrimers containing $\pi$-conjugated dendrons are expected to present better energy transfer properties than systems for which $\pi$-conjugation is completely disrupted, as indicated by the work of Burn and Samuel on porphyrin dendrimers with stilbene dendrons for instance. ${ }^{1 \mathrm{k}}$ The meso-phenyl units of the TPP-core molecule have two positions easy to functionalize (para and meta), so the corresponding dendrimers were then synthesized. The optical properties of these porphyrin-based 
dendrimers, featuring 2-fluorenyl containing dendrons with extended $\pi$-manifolds on these positions, were then studied (Fig. 1). Such systems present increasing numbers of terminal fluorenyl units at their periphery, going from 4 to 8 to 16 (TPP1, TPP2 and TPP3, respectively). We have shown that the conjugation between the TPP porphyrin core and the unsaturated dendrons is more effective in the para-functionalized systems than in the metaones. This better conjugation improves the photophysical properties of the para-substituted compounds (TPP1) over the meta-substituted ones (TPP2, TPP3), ${ }^{11}$ encouraging us to consider, the 2,7-fluorenyl unit as a new spacer, in replacement of the 1,4-phenyl unit. 


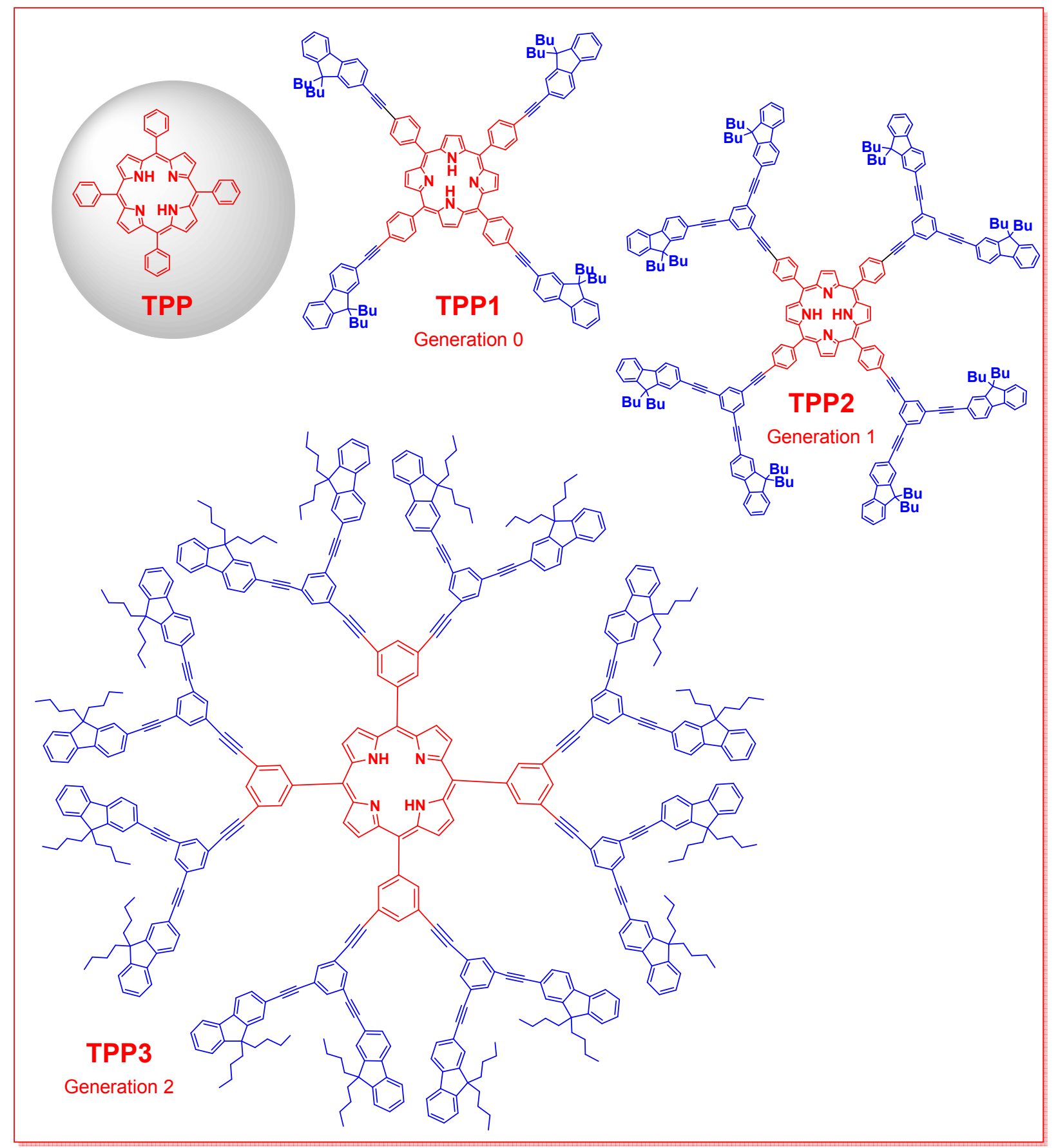

Fig. 1. Molecular structures of TPP-cored porphyrin dendrimers TPP1-TPP3 and their reference TPP

A series of related compounds in which 2,7-fluorenyl groups was connected directly to the meso positions of the central porphyrin core (i.e. a dendritic architecture featuring TFP instead of TPP as a central core) and still possessing fully conjugated peripheral arms incorporating fluorene units at both terminal and internal positions was then developed. 


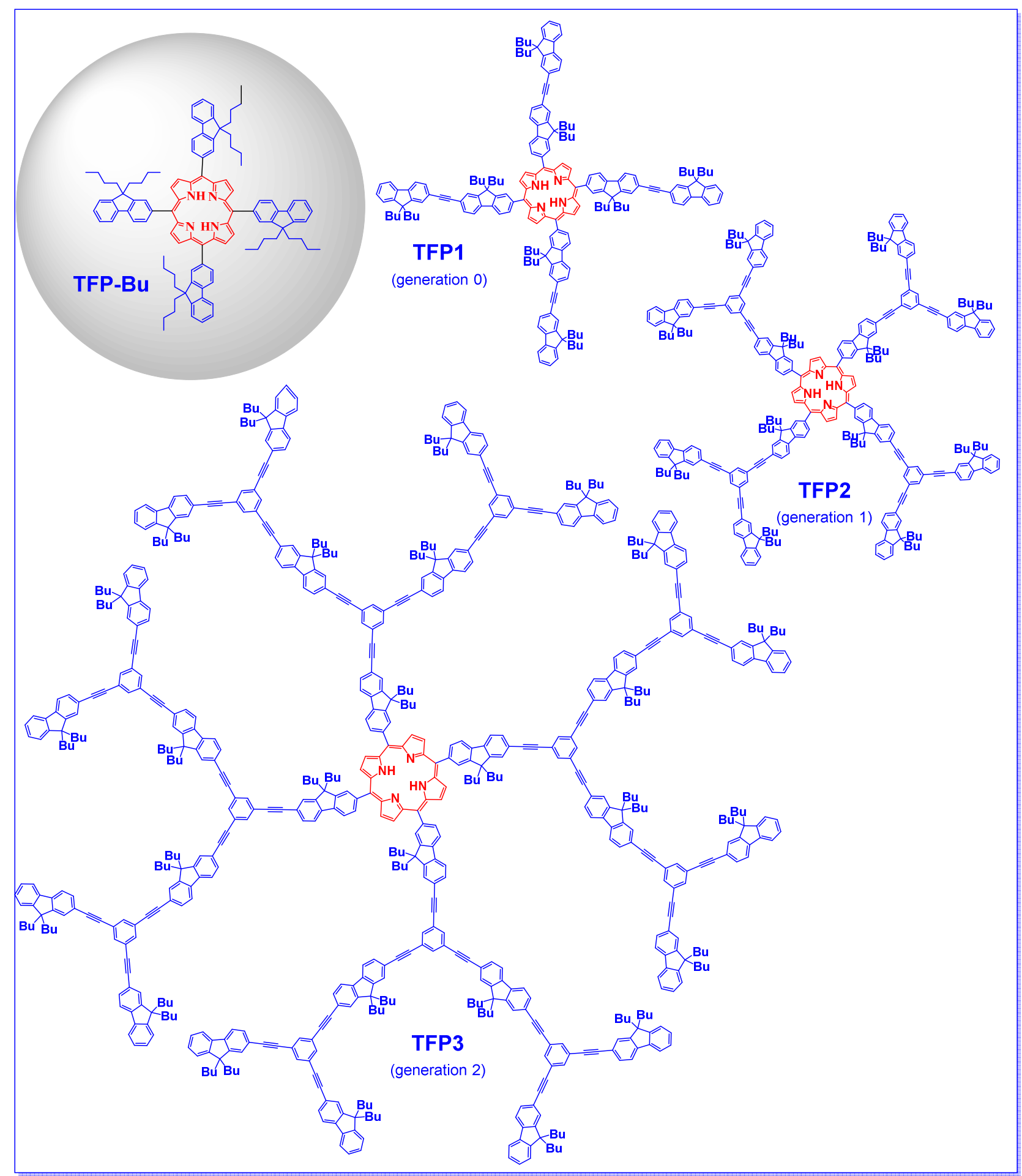

Fig. 2. TFP-cored porphyrin dendrimers TFP1, TFP2 and TFP3 and the corresponding reference compound TFP-Bu

A versatile synthetic protocol allowed us to easily introduce fluorenyl units as internal chromophores (behaving also as antennae). The effect of this structural variation on the photophysical properties of the resulting dendrimers was then explored. The dendrimers with increasing generations going from 1 to 3, were called TFP1, TFP2 and TFP3, respectively (represented in Fig. 2). ${ }^{1 \mathrm{~m}}$ In terms of photophysical properties, this TFP series exhibit 
remarkably high luminescence quantum yields (20-24\%) again thanks to a very efficient energy transfer (ET) from the peripheral fluorenyl units toward the central porphyrin core. This process is plainly apparent for dendrimers TFP1 and TFP2, but contrasts with the dual emission (blue and red) observed for the big TFP3 compound featuring the largest dendrons at the meso positions. Such a size-limit to the ET was expected considering the tilted conformation adopted by the inner meso-fluorenyl groups bearing the peripheral dendrons. In spite of that non-optimal $\pi$-conjugation, the one-photon brightness of these compounds increases almost linearly with the number of fluorenyl groups in the peripheral arms, in line with the existence of the antenna effect previously mentioned. ${ }^{1 \mathrm{~m}}$ To improve further the photophysical performance of such dendrimeric systems, with the aryl groups tilted conformations should be replaced by another unit permitting to achieve co-planarity between the central core and aromatic system of the peripheral dendrons. In particular, this can be done by using a meso-substituted tetra alkynyl porphyrin as the central unit. We therefore turned our interest toward meso-ethynylporphyrins.

The first porphyrins of this kind, substituted by one or two alkynyl groups, were initially targeted as precursors for the elaboration of conducting polymers, ${ }^{2-3}$ non-linear optical (NLO) materials, ${ }^{4,5}$ photosynthetic models ${ }^{6,7}$ and enzyme mimics. ${ }^{8-10}$ Most of these alkynyl-meso substituted porphyrins contained only one or two ethynyl moieties. These macrocycles turned out to present a strong bathochromic shift of their first absorptions relative to tetraphenylporphyrin. ${ }^{11-15}$ This is due to the direct conjugation of the $18 \pi$-electronic system of the macrocycle over the alkynyl group to the terminal aromatic moieties. As a result, the Soret (B-) band and Q-bands are significantly altered. ${ }^{11}$ In consequence, the color of these porphyrins in solution turns to a brilliant green departing from the typical red color of tetraphenylporphyrin. Hence the trivial name of Chlorphyrins was given for arylethynylmeso-substituted porphyrins. ${ }^{12-15}$ In the tetralkynyl series, in 1992, Anderson reported a tetrasubstituted derivative: 5,10,15,20-tetra-trimethylsilylethynyl-porphyrin $\left(\mathrm{H}_{2} \mathbf{1}\right)$ (see Fig. 3) which was isolated in moderate yield $(14 \%) .{ }^{11}$ The same year, Hevesi obtained a closely related compound $\left(\mathrm{H}_{2} \mathbf{2}\right)$, but with methyl endgroups substituent rather than TMS ones. This new tetra-alkynylporphyrin was isolated with an even low yield (around 1\%). ${ }^{16}$ Finally, the corresponding aryl-ethynyl derivative (5,10,15,20-tetra-phenylethynyl)-porphyrin $\left(\mathrm{H}_{2} \mathbf{3}-\mathbf{R}\right)$ was also reported the same year, with a yield of $2 \%{ }^{16}$ Subsequently, Milgrom reported the synthesis of related compounds with octyl or nonyloxy chains appended in the para positions of the four phenyl groups $\left(\mathrm{H}_{2} \mathbf{3}-\mathbf{R}\right)$ to increase the solubility of these compounds. ${ }^{12}$ These last 
porphyrins $\left(\mathrm{H}_{2} 2\right.$ and $\left.\mathrm{H}_{2} 3-\mathrm{R}\right)$ were synthesized with the aim of developing highly conjugated porphyrin polymers and arrays by assembling these building blocks together. ${ }^{12,16}$

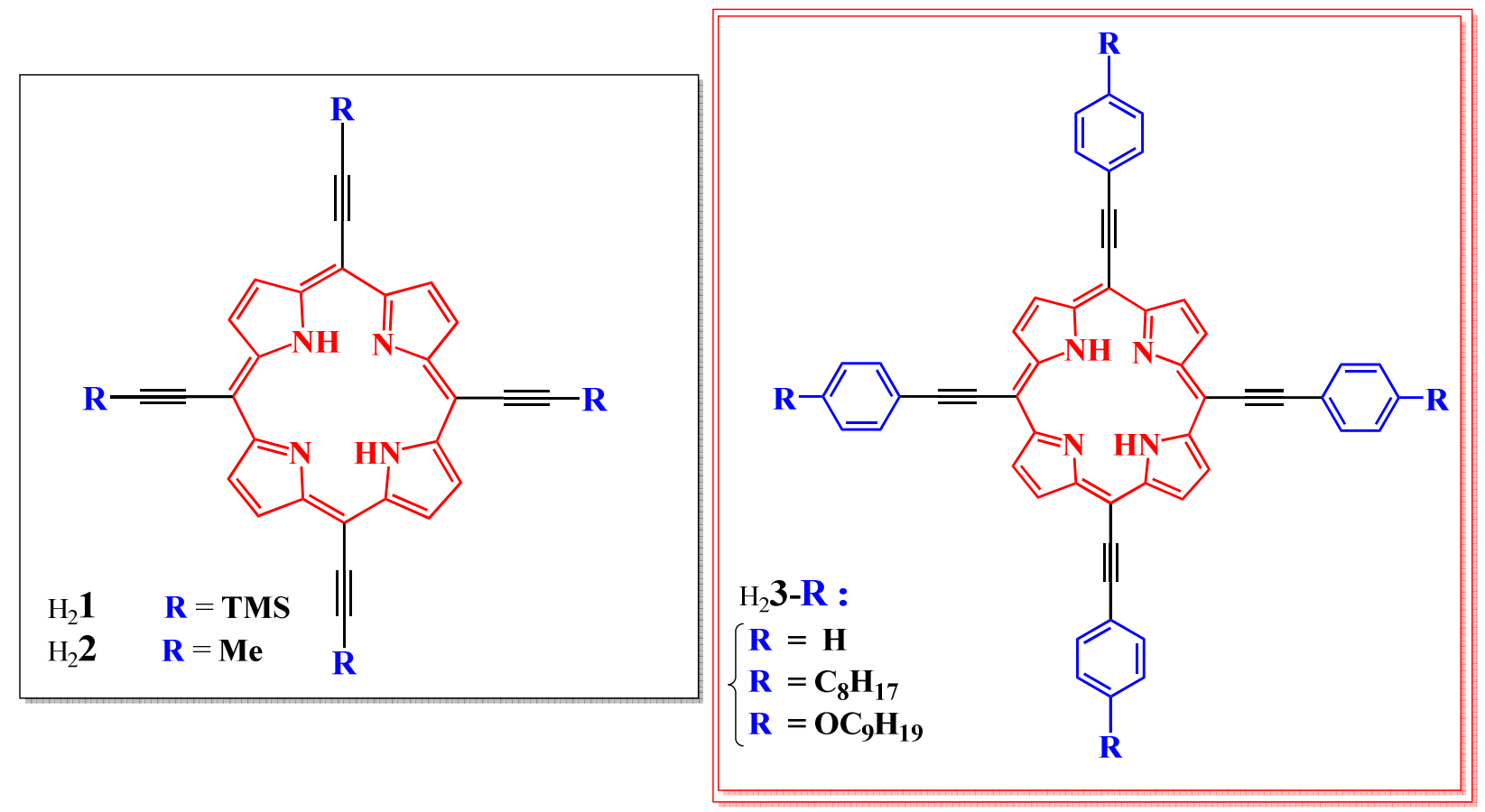

Fig. 3. Molecular structures of reported meso-alkynyl porphyrins $\left(\mathrm{H}_{2} \mathbf{1}, \mathrm{H}_{2} \mathbf{2}\right.$ and $\left.\mathrm{H}_{2} \mathbf{3}-\mathrm{R}\right)$

Based on these tetra-alkynyl meso-substituted precursors, we believe that the related meso-tetra-alkynyl fluorenyl porphyrin (TAFIP) composed of one central porphyrin substituted at its meso positions by four alkynylfluorenyl units could constitute an interesting platform for designing new dendrimers for theranostics (Fig. 4). Indeed expending the $\pi$ manifold should increase the 2PA and bring about a red shift in emission and absorption. We have therefore synthesized TAFIP porphyrin as a model compound to study its optical properties and compare them to those of TFP-Bu taken as reference. TAFIP porphyrin will also be compared to the known tetraalkynyl porphyrins $\mathrm{H}_{2} \mathbf{1}, \mathrm{H}_{2} \mathbf{2}$ and $\mathrm{H}_{2} \mathbf{3}-\mathbf{R}\left(\mathrm{R}=\mathrm{H}, \mathrm{C}_{8} \mathrm{H}_{17}\right.$, $\mathrm{OC}_{9} \mathrm{H}_{19}$ ). This molecular assembly might (i) possess the remarkable fluorescence yield and brightness of $\mathbf{T F P}^{1 \mathrm{i}}$ precursor, (ii) present a fully conjugated and extended $\pi$-manifold which will favour the 2PA and also redshift the 2PA and the emission. As usual (see Fig. 1,2) butyl chains will be connected to the peripheral fluorenyl units (in the 9 position) to improve the solubility of the compound in organic solvents. 

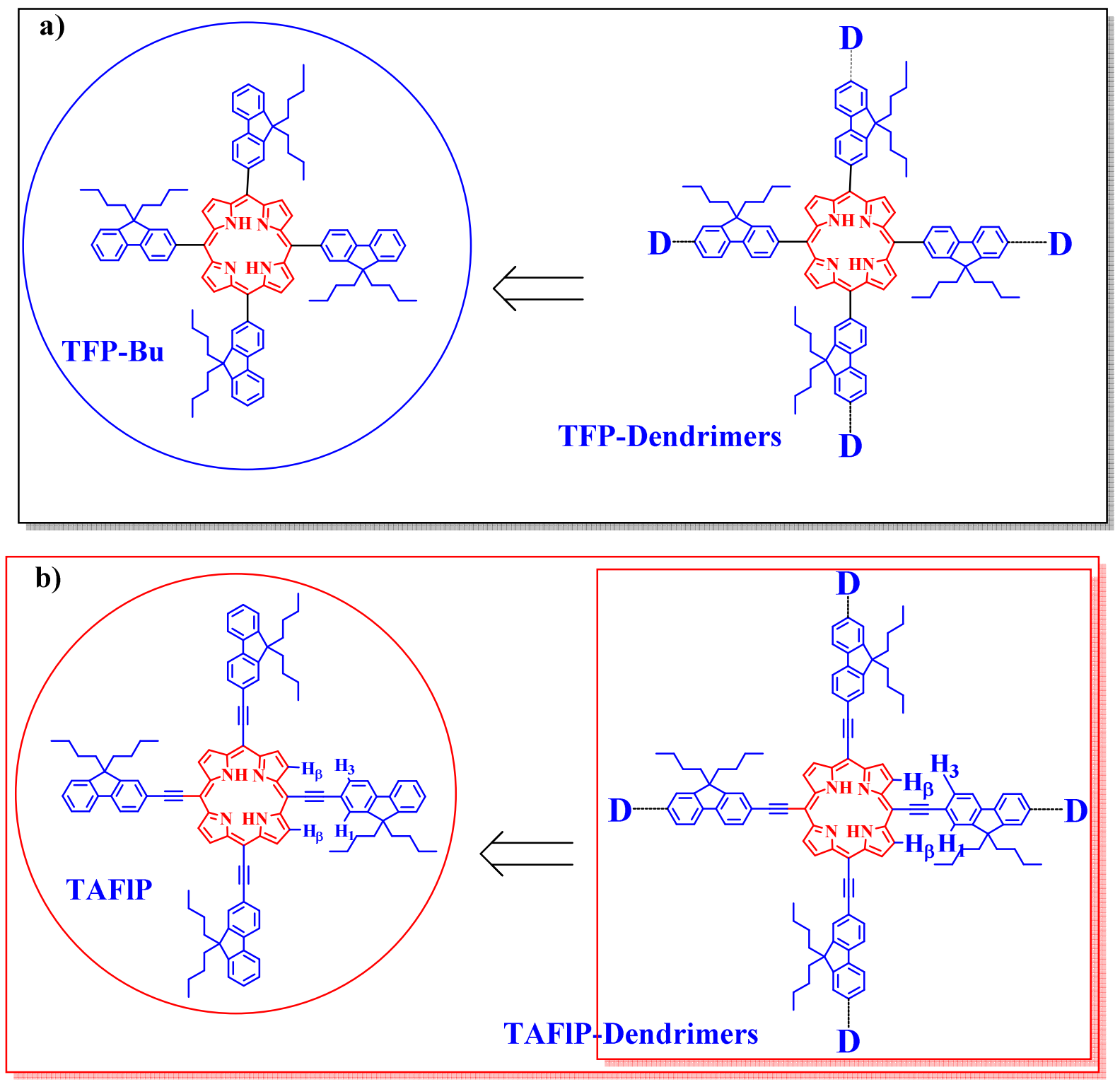

Fig. 4. a) Structure of reference compound TFP-Bu and corresponding TFP based dendrimers; b) target compound: new meso-alkynyl fluorenyl porphyrin TAFIP allowing the design of new TAFIPbased dendrimers

\section{RESULTS AND DISCUSSION}

\section{Synthesis and characterization}

To synthesize TAFIP, two different ways were tested. A first trial at isolating this molecule was done via $\mathrm{H}_{2} \mathbf{1}^{2 \mathrm{a}}$ As shown in Scheme 1: one equivalent of the commercial 3(trimethylsilyl)-2-propynal and pyrrole were dissolved in distilled $\mathrm{CHCl}_{3}$ under argon. The reaction was conducted by adapting the reaction protocol given by Anderson in the literature 
for $\mathrm{H}_{2} \mathbf{1},{ }^{11}$ and it allowed the isolation of $\mathrm{H}_{2} \mathbf{1}$ with a low yield $(14 \%) .{ }^{11}$ Considering the large quantity of $\mathrm{H}_{2} \mathbf{1}$ required for the next step and also the high price of the starting material (3(trimethylsilyl)-2-propynal); this approach was eventually not pursued, and a second approach was tested.
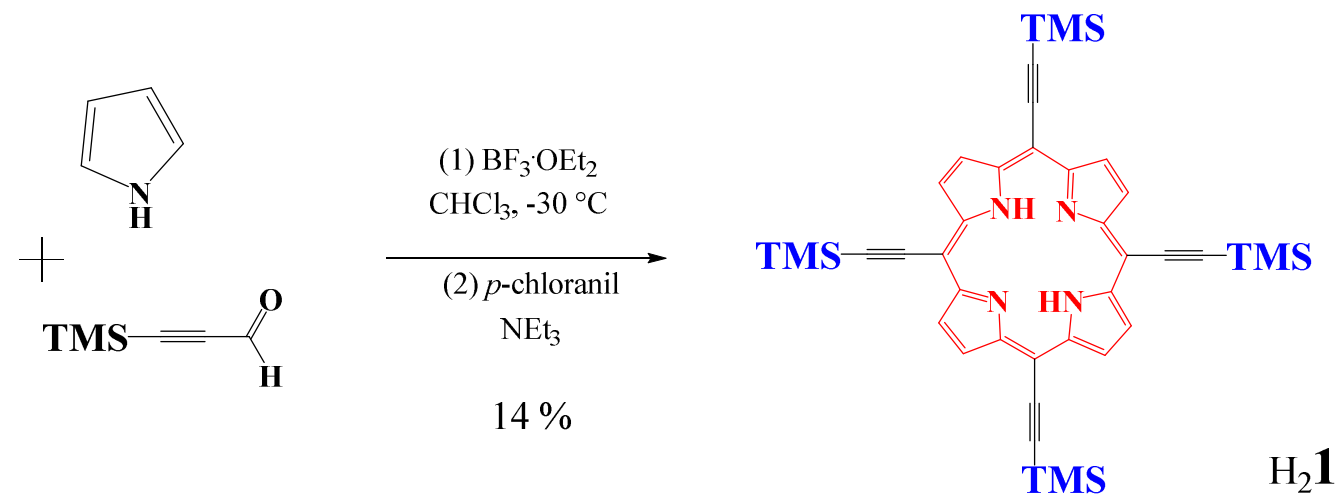

Scheme 1. Syntheses of intermediate $\mathrm{H}_{2} \mathbf{1}$, following Anderson's work up ${ }^{11}$

In the second approach, 9,9-dibutyl-fluorenyl-2-propiolaldehyde $\mathbf{3}$ was synthesised first as a precursor and then assembled to obtain the desired TAFIP under Lindsey's conditions (Scheme 2). The intermediate alkyne 2 was prepared in three steps as described earlier, ${ }^{11}$ giving the precursor 3 by exchange of the terminal proton and carboxylation. ${ }^{17}$ The desired new meso-alkynyl fluorenyl porphyrin TAFIP was finally isolated albeit with a low yield (3\%). This second synthetic approach (Scheme 2), using for each step well known reactions and leading to isolation of the precursor $\mathbf{3}$ in good yields was eventually selected, in spite of its comparatively final low yield, mostly for practical and cost-related reasons. 

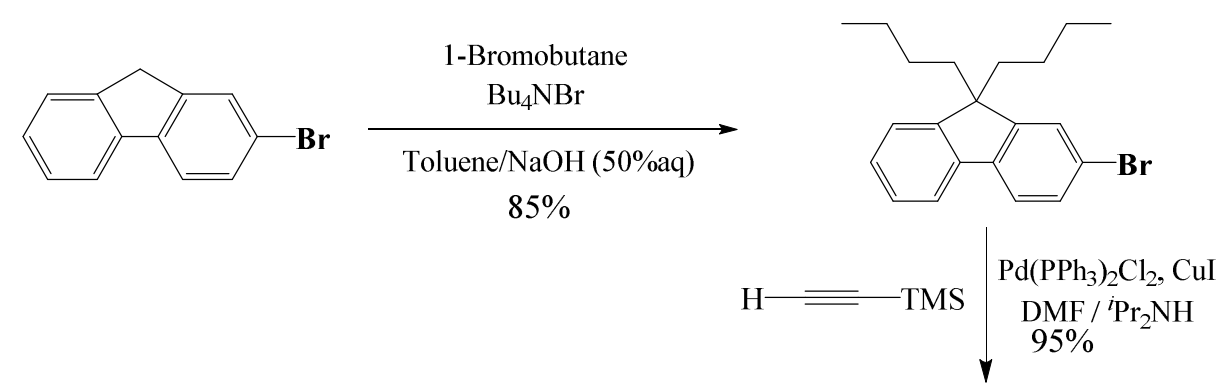

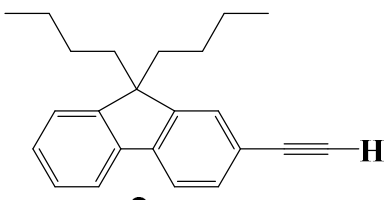

2

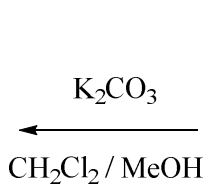

$92 \%$
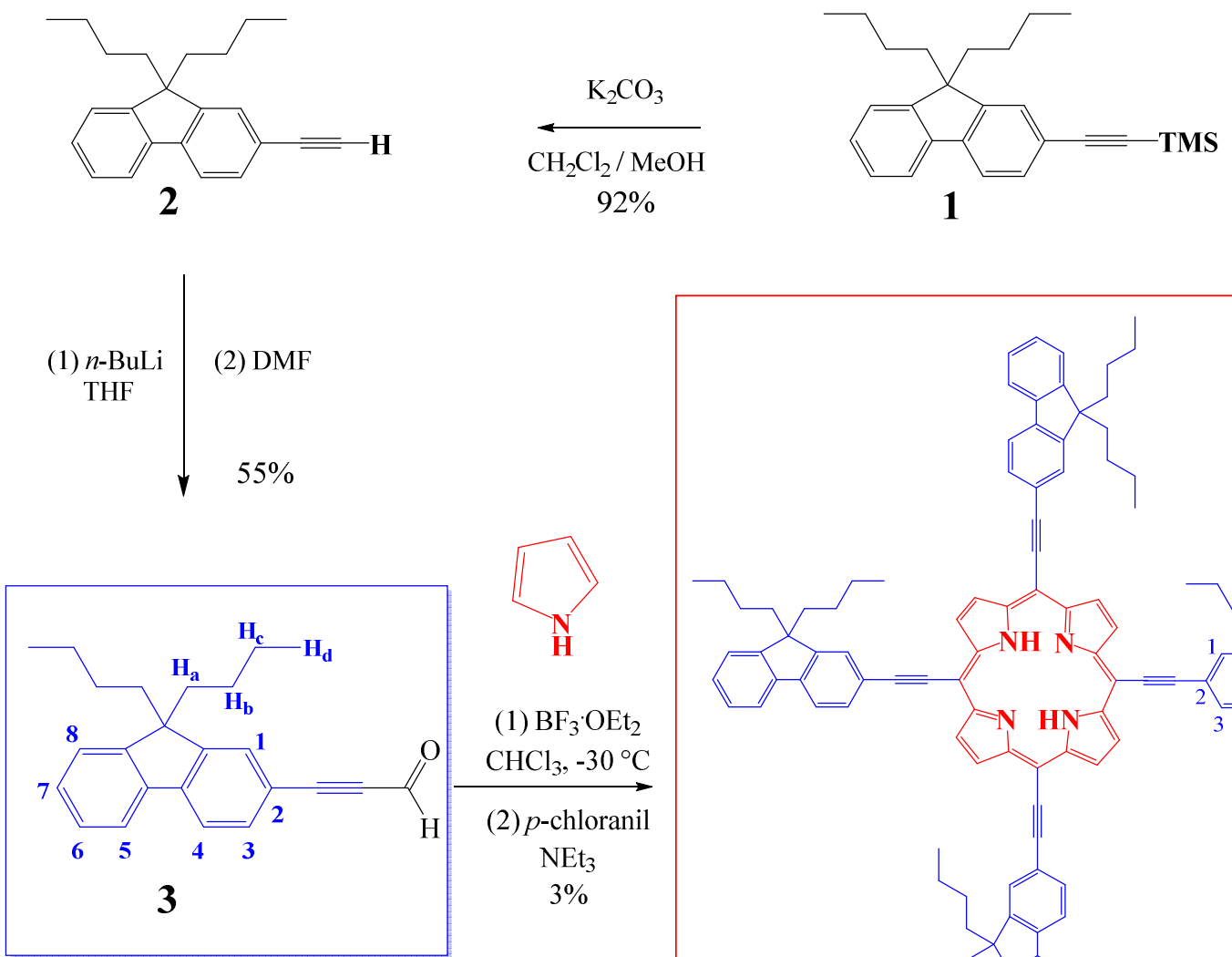

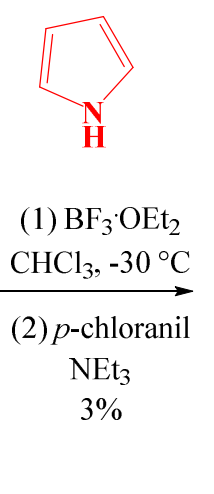

(1) $\mathrm{BF}_{3} \cdot \mathrm{OE}$ (2) $p$-chloranil $\mathrm{NEt}_{3}$ $3 \%$

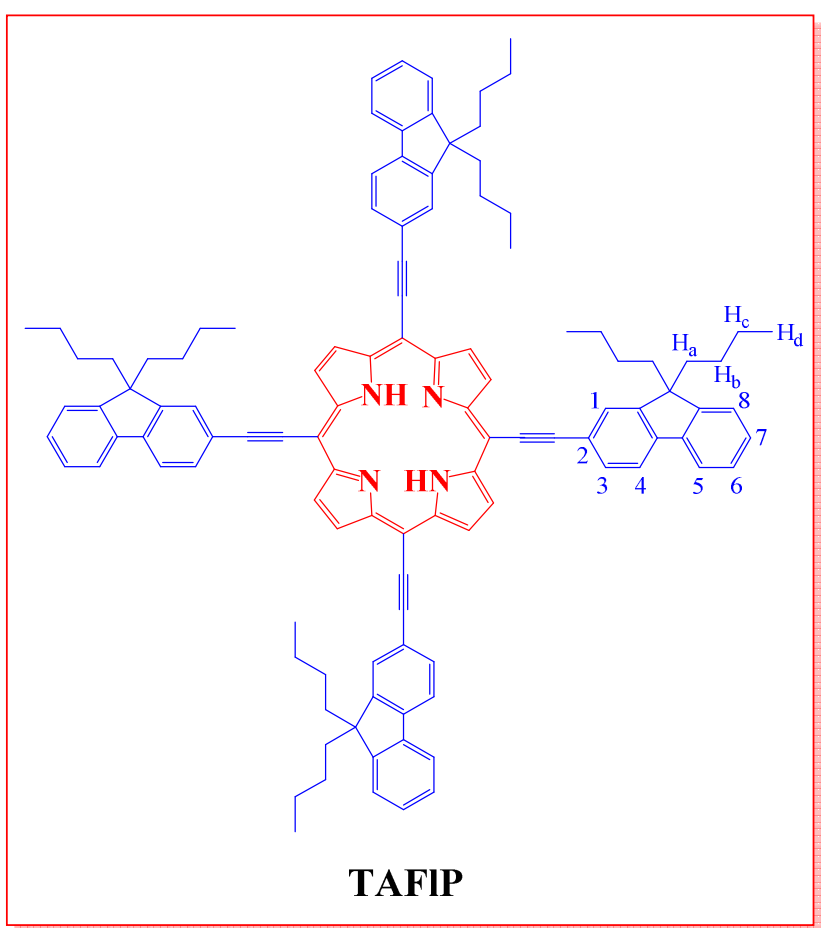

Scheme 2. Synthesis of the new 9,9-dibutyl-fluorenyl-2-propiolaldehyde 3 and of meso-alkynyl fluorenyl porphyrin TAFIP

The new compounds were characterized by usual methods. The ${ }^{1} \mathrm{H}$ NMR spectra of the known 9,9-dibutyl-fluorenyl-2-carboxaldehyde and of the new (9,9-dibutyl-fluorenyl)-2propiolaldehyde (3) are shown in Fig. 5. We observe that the aldehyde proton of new compound 3, at $9.46 \mathrm{ppm}$, is shifted to higher field (+0.62 ppm) upon the introduction of the alkynyl function. The multiplets corresponding to aromatic, as well as $n$-butyl protons, present similar shifts for $\mathbf{3}$ compared to 9,9-dibutyl-fluorenyl-2-carbaldehyde, but of lower magnitude. 


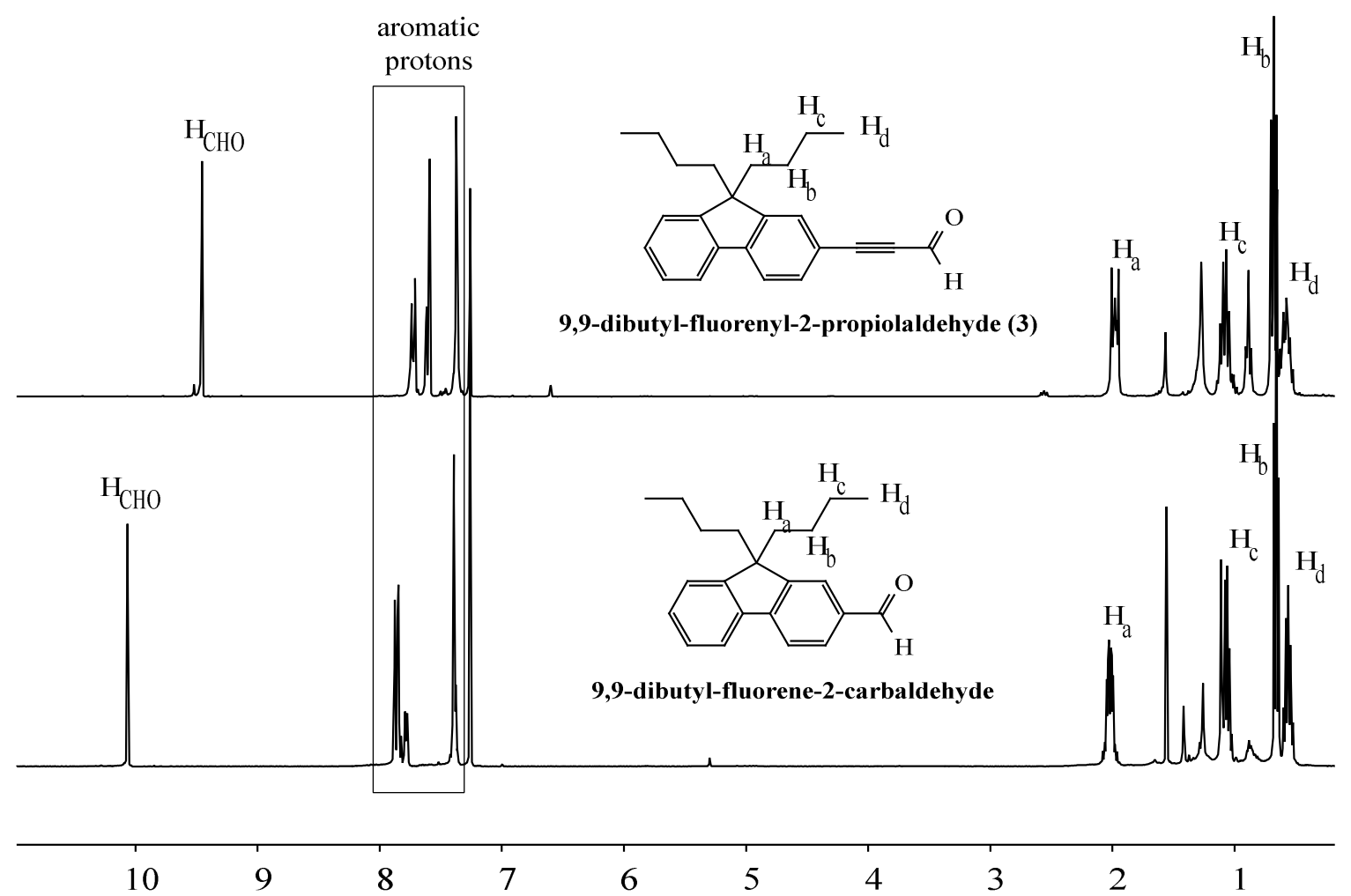

Fig. 5. Comparison of complete ${ }^{1} \mathrm{H}$ NMR spectra of 9,9-dibutyl-fluorenyl-2-carbaldehyde and new (9,9-dibutyl-fluorenyl)-2-propiolaldehyde (3)

The corresponding meso-alkynyl fluorenyl porphyrin (TAFIP) was also characterized by ${ }^{1} \mathrm{H}$ NMR. The partial spectrum is compared to reference TFP-Bu in $\mathrm{CD}_{2} \mathrm{Cl}_{2}$ (Fig. 6). As shown, the singlet at $9.69 \mathrm{ppm}$, corresponding to eight $\beta$-pyrrolic protons is shifted to lower field compared to the corresponding signal of TFP-Bu at $8.92 \mathrm{ppm}$. This can be because these $\beta$-pyrrolic protons are further removed from ring currents field of the aromatic units in the arms. An alternative explanation is that they experience a smaller ring current from the porphyrin cycle. The second explanation is also supported by the fact that the singlet at -1.36 ppm of NH protons is strongly shifted to lower field compared to that at $-2.57 \mathrm{ppm}$ for TFPBu. Thus it seems that the combination of the alkynyl bridges and fluorenyl units also causes a decreased electron density at the porphyrin ring. On the contrary, the electron density of fluorenyl arms seems to be partially increased, leading to signals for aromatic protons $\left(\mathbf{H}_{\mathbf{1}-\mathbf{5}}\right)$ at higher field for TAFIP than for TFP-Bu. 

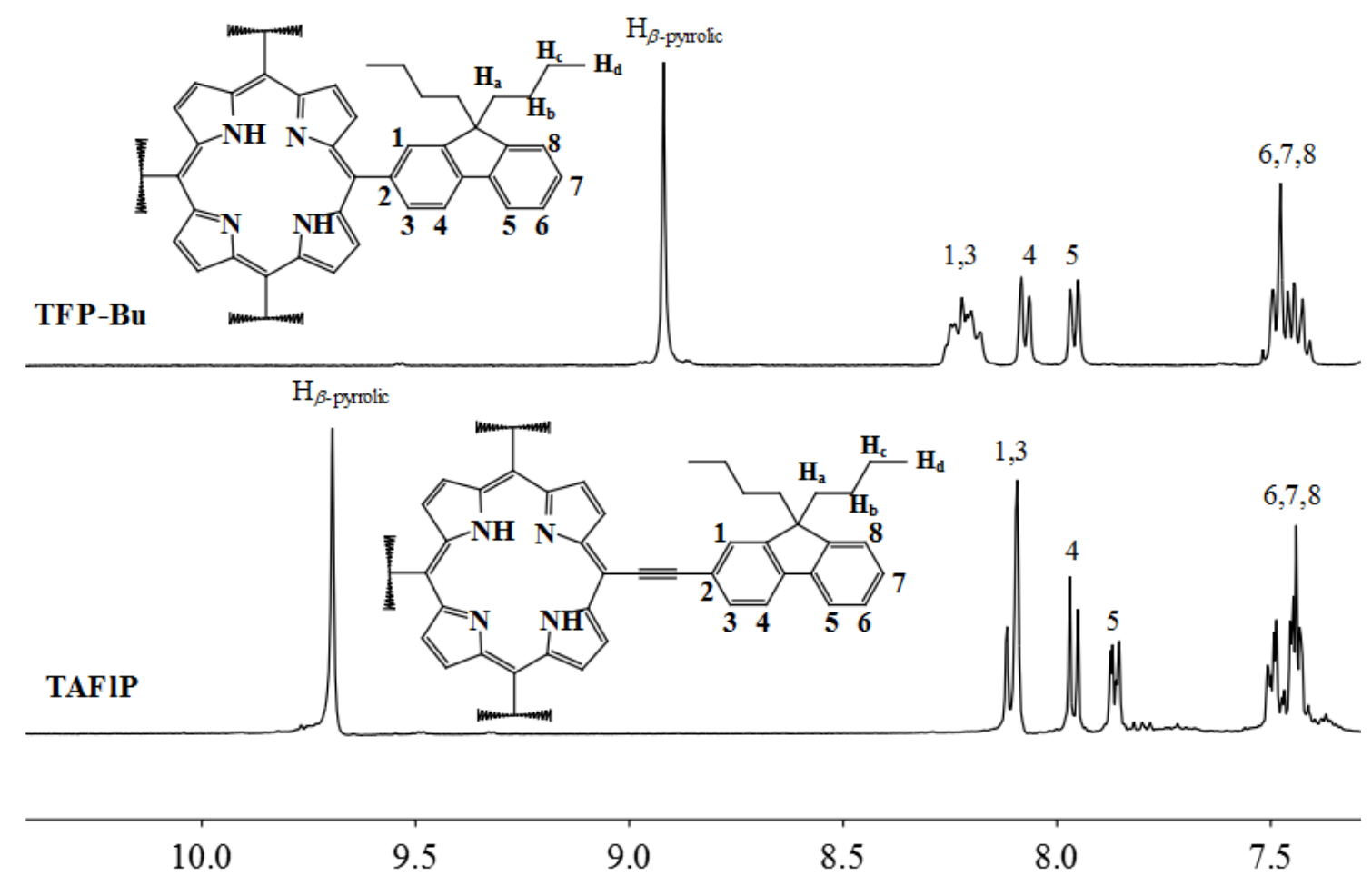

Fig. 6. The partial ${ }^{1} \mathrm{H}$ NMR spectra of new meso-alkynyl fluorenyl porphyrin TAFIP compared to reference TFP-Bu

UV-visible absorption and emission spectra were next recorded for the new porphyrin (TAFIP) in $\mathrm{CH}_{2} \mathrm{Cl}_{2}$ solution (HPLC level) at room temperature. Molecules with similar

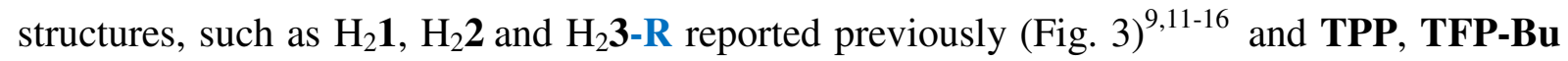
were chosen as references to analyze the influence of the triple bond introduction on the optical properties. When compared to meso-tetra-alkynylporphyrins, the fluorenyl rings of TAFIP extend the $\pi$-manifold of the chromophore, resulting in a bathochromic shift of all the absorption bands compared to $\mathrm{H}_{2} \mathbf{1}, \mathrm{H}_{2} \mathbf{2}$ and $\mathrm{H}_{2} \mathbf{3}-\mathbf{R}$, but also compared to TFP-Bu. TAFIP has several characteristic features in the UV-visible region (Fig. 7): (i) an intense Soret-band around $479 \mathrm{~nm}$ with a shoulder at $486 \mathrm{~nm}$ and two red shifted Q-bands at 661 and $748 \mathrm{~nm}$, characteristic of the porphyrin macrocycle, and (ii) an extra absorption due to alkynylfluorenyl antennae $(\mathbf{A F l})$, around $250-400 \mathrm{~nm}\left(\lambda_{\text {Dendron }}=319 \mathrm{~nm}\right)$ which corresponds to a $\pi^{*} \leftarrow \pi$ transition of the conjugated dendron. This strong absorption, largely fluorenylbased, is absent for reference TFP-Bu, suggesting that the unconjugated meso-fluorenyl groups of TFP-Bu absorb above $270 \mathrm{~nm},{ }^{1 \mathrm{~m}}$ whereas those of TAFIP, conjugate with the porphyrin core appear strongly red shifted and show up more intense. 
Table 1. Photophysical data of new meso-alkynyl fluorenyl porphyrin TAFIP and reported $\mathrm{H}_{2} 1, \mathrm{H}_{2} 2$ and $\mathrm{H}_{2}$ 3-R and references TFP-Bu, TPP

\begin{tabular}{|c|c|c|c|c|c|c|c|}
\hline \multirow{2}{*}{\multicolumn{3}{|c|}{ UV-visible absorption /nm }} & & & & \multirow{4}{*}{$\Phi_{\mathrm{fl}} / \%$} & \multirow{4}{*}{$\tau / \mathrm{ns}$} \\
\hline & & & & \multicolumn{2}{|c|}{$\begin{array}{l}\text { Emission } / \mathrm{nm} \\
\text { excited at } \lambda_{\text {Soret }}\end{array}$} & & \\
\hline & $\lambda_{\text {Soret }}$ & $\lambda_{\text {Q-bands }}$ & & & \\
\hline TPP & 419 & $515,548,592,647$ & & $\mathrm{Q}(0,0$ & $\mathrm{Q}(0,1)$ & & \\
\hline TFP-Bu & 426 & $520,557,593, \mathbf{6 5 0}$ & TPP & 653 & 721 & 11 & 8,6 \\
\hline $\mathrm{H}_{2} \mathbf{1}^{a}$ & 451 & $567,606,646,710$ & TFP & 663 & 730 & 24 & 8,0 \\
\hline $\mathrm{H}_{2} 2^{a}$ & 446 & $517,563,602,647,708$ & TFP-Bu & 660 & 724 & 20 & 8.2 \\
\hline $\mathrm{H}_{2} \mathbf{3}_{\mathrm{H}}{ }^{a}$ & 463 &, 717 & TAFIP & 760 & - & - & - \\
\hline $\mathrm{H}_{2} \mathbf{3}_{\mathrm{C} 8 \mathrm{H} 17}$ & 466 & $599, \mathbf{6 4 2}, \quad 673,737$ & & & & & \\
\hline $\mathrm{H}_{2} \mathbf{3}_{\mathrm{OC} 9 H 19}$ & 472 & $600, \mathbf{6 5 3}$ & & & & & \\
\hline TAFIP & $\begin{array}{c}479 \\
(486)\end{array}$ & , 748 & & & & & \\
\hline
\end{tabular}

${ }^{a}$ data from lit. [11-16]

When going from reference TFP-Bu to new porphyrin TAFIP, a strong red shift $(\Delta \lambda$ $=53 \mathrm{~nm}$ ) can be clearly observed on the normalized absorption spectra for the porphyrin based bands due to the alkynyl bridges (Soret-band and Q-bands in Figure 7). It should also be noticed that generally, free based porphyrins have four obvious Q-bands, but for TAFIP, only two coalesced Q-bands with and hyperchromic effect are observed in the visible region. In addition, there is a marked increase in the main $\mathrm{Q}$ band absorption $(661 \mathrm{~nm})$ relative to that of the B band (479 $\mathrm{nm})$, and the second Q band $(748 \mathrm{~nm})$ appears as a smaller band on the right-side of this main $\mathrm{Q}$ band absorption.

We can notice that the derivative $\mathrm{H}_{2} \mathbf{3}-\mathbf{H}$, which possess similar ethynylaryl structures than TAFIP, presents similar spectral profiles and show only two Q-band absorptions. In contrast, the para octyl substituted derivate of $\mathrm{H}_{2} 3-\mathbf{R}$ presents four Q-bands but very strongly red shifted and in this case, this red shift is even larger, going up to $\Delta \lambda=79 \mathrm{~nm}$. The porphyrin $\mathrm{H}_{2} 2$ also presents four classical Q-bands in the visible region. ${ }^{12,16}$ Likewise, the aryl rings of the tetra-phenylethynylporphyrin $\left(\mathrm{H}_{2} \mathbf{3}-\mathbf{H}\right)$ by extending the porphyrin chromophore 
result in a bathochromic shift for the B- and Q- absorption bands compared to those of porphyrin. Thus, compared to short tetra-phenylporphyrin (TPP), the B band of porphyrin $\mathrm{H}_{2} \mathbf{1}$ is red-shifted to $451 \mathrm{~nm}$. Also, by replacing TMS groups of $\mathrm{H}_{2} \mathbf{1}$ with aryl groups $\left(\mathrm{H}_{2} \mathbf{3}-\right.$ $\mathbf{R})$, increases the B- and Q- band red shifts even further.

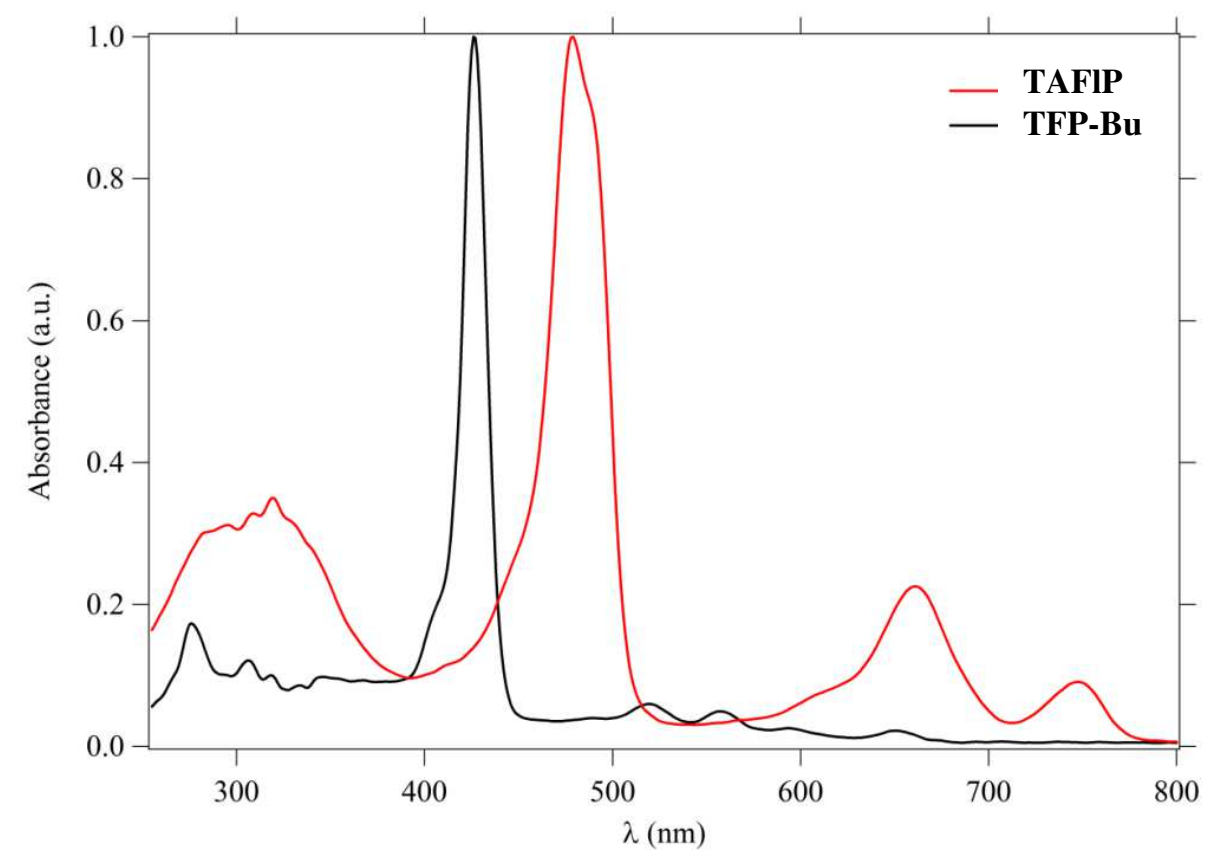

Fig. 7. Normalized absorption UV-visible spectra of TAFIP and reference TFF-Bu in $\mathrm{CH}_{2} \mathrm{Cl}_{2}(\mathrm{HPLC}$ grade) at room temperature.

The emission spectra of TAFIP and the reference compound TFP-Bu were measured in $\mathrm{CH}_{2} \mathrm{Cl}_{2}$ (HPLC grade) at room temperature. Upon excitation in their Soret-band, they both exhibit the characteristic porphyrin emission peaks $\mathrm{Q}(0,0)$ (Fig. 8). The lowest energy Qband absorption is at $748 \mathrm{~nm}$, while the corresponding fluorescence band appears at $760 \mathrm{~nm}$. The new tetra-fluorenylethynylporphyrin spectra are also characterized by small Stokes shifts $(\sim 12 \mathrm{~nm})$ but slightly larger than for TFP-Bu derivatives $(\sim 10 \mathrm{~nm})^{19}$ similar to the shift reported in 1998 , for 5,10,15,20 tetra-arylethynyIporphyrinato zinc(II) complexes (13 nm). ${ }^{18}$ The proximity of these two bands indicates that the nuclear configurations of the ground and excited states of TAFIP are nearly similar. Whereas reference TFP-Bu emits a typical red luminescence, with two Q bands (660 and $724 \mathrm{~nm}$ ), for new TAFIP only a strong single band $\mathrm{Q}(0,0)$ could be detected in the visible region with a maximum at $760 \mathrm{~nm}$ with a large red shift $(\Delta \lambda=100 \mathrm{~nm})$ compared to TFP-Bu. This intense $\mathrm{Q}(0,0)$ emission band has a part of its emission located in near infrared region (shadowed on Fig. 8). Thus, as for absorption, the 
presence of the four ethynyl groups results in a significant red shift in the fluorescence peak maxima relative to TPP and TFP-Bu derivatives, resulting in emission located partly in the near infra-red region of the spectrum. The detector of the Edinburgh FS920 Fluorimeter (Xe900) can only collect the signal at the maximum wavelength of $900 \mathrm{~nm}$, so for the moment eventually weaker emission band $\mathrm{Q}(0,1)$ could not be detected and in consequence, the quantum yield of this new porphyrin TAFIP is calculated but maybe under evaluate. The fluorescence quantum yields, measured in $\mathrm{CH}_{2} \mathrm{Cl}_{2}$ for this new porphyrin TAFIP is found to be $24 \%$ albeit similar to TFP (24\%), and higher then TFP-Bu (20\%). In agreement with what had already been noted earlier about fluorescence. Indeed it was proofed that fluorescence quantum yield values are significantly higher for the arylethynyl derivatives $\left(\phi_{\mathrm{fl}}>20 \%\right)$ and are among the highest values observed for porphyrinic species. ${ }^{19}$ So measurement must be repeated on a fluorimeter allowing detection further in the near IR range.

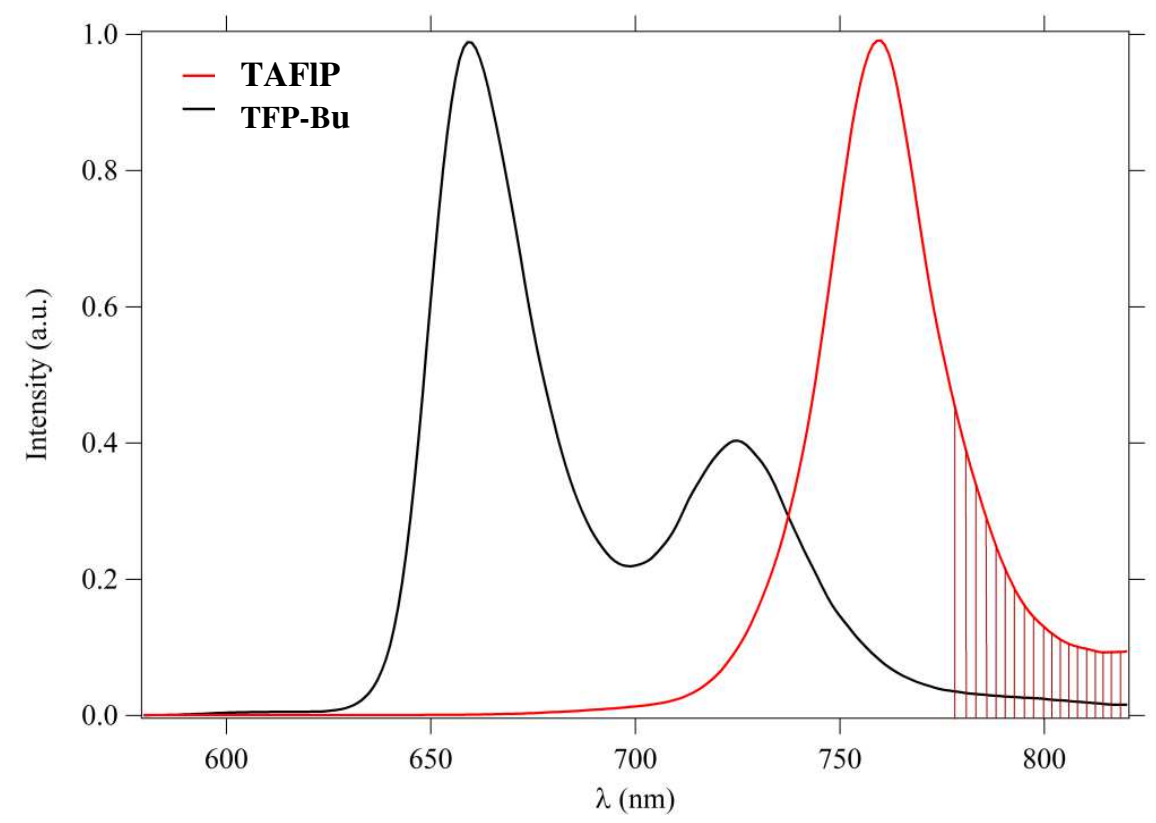

Fig. 8. Comparison of emission spectra of TAFIP and reference TFP-Bu in the visible region, upon excitation in their Soret-band

\section{EXPERIMENTAL}

\section{Materials}

Unless otherwise stated, all solvents used in reactions were distilled using common 
purification protocols, ${ }^{20}$ except DMF and ${ }^{\mathrm{i}} \mathrm{Pr}_{2} \mathrm{NH}$, which were dried on molecular sieves (3 $\AA$ ). Compounds were purified by chromatography on silica gel using different mixtures of eluents as specified. ${ }^{1} \mathrm{H}$ and ${ }^{13} \mathrm{C}$ NMR spectra were recorded on BRUKER Ascend 400 and 500 at $298 \mathrm{~K}$. The chemical shifts are referenced to internal tetramethylsilane. High-resolution mass spectra were recorded on different spectrometers: a Bruker MicrOTOF-Q II, a Thermo Fisher Scientific Q-Exactive in ESI positive mode and a Bruker Ultraflex III MALDI Spectrometer at CRMPO (centre regional de mesures physiques de l'Ouest) in Rennes. Reagents were purchased from commercial suppliers and used as received. Compounds 9,9dibutyl-7-((trimethylsilyl)ethynyl)-fluorene-2-carboxaldehyde and 2-ethynyl-9,9-dibutylfluorene (2), were synthesized as described earlier. ${ }^{11,1 \mathrm{~m}}$

\section{Spectroscopic Measurements}

All photophysical properties have been performed with freshly-prepared airequilibrated solutions at room temperature (298 K). UV-Vis absorption spectra were recorded on a BIO-TEK instrument UVIKON XL spectrometer or on a Jasco V-570 spectrophotometer. Steady-state fluorescence measurements were performed on dilute solutions $\left(\mathrm{ca} .10^{-6} \mathrm{M}\right.$, optical density $\left.<0.1\right)$ contained in standard $1 \mathrm{~cm}$ quartz cuvettes using an Edinburgh Instrument (FLS920) spectrometer in photon-counting mode. Fully corrected emission spectra were obtained, for each compound, after excitation at the wavelength of the absorption maximum, with $A_{\lambda \varepsilon x}<0.1$ to minimize internal absorption.

\section{Synthesis}

9,9-dibutyl-fluorenyl-2-propargylaldehyde (3): In a Schlenk tube, a mixture of 9,9dibutyl-2-ethynyl-fluorene (2) (1.03 g, $3.41 \mathrm{mmol}, 1$ equiv) was dissolved in dried THF (10 $\mathrm{mL}$ ). The reaction medium was degassed by freeze-pump-thaw for three times and cooled to $-78{ }^{\circ} \mathrm{C}$ in a liquid nitrogen-acetone bath. At $-78{ }^{\circ} \mathrm{C}, n$-BuLi (2.60 mL, $4.09 \mathrm{mmol}, 1.2$ equiv) was injected dropwise to the previous mixture over $30 \mathrm{~min}$. Then the system was kept stirring at $-78{ }^{\circ} \mathrm{C}$ for more than $3 \mathrm{~h}$. Subsequently dry DMF $(0.53 \mathrm{~mL})$ was injected in the medium and the reaction was maintained under stirring at $-78{ }^{\circ} \mathrm{C}$ for another hour. The reaction was then taken away from cooling bath and stirred overnight at room temperature. At last, saturated $\mathrm{NH}_{4} \mathrm{Cl}$ (aq.) was injected (for quenching the reaction). The mixture was extracted with ethyl acetate/water mixtures. After evaporation of the volatiles, the residue was purified by silica chromatography using heptane/ $\mathrm{CH}_{2} \mathrm{Cl}_{2}$ (5:1) as eluent. The desired compound 9,9dibutyl-fluorenyl-2-propiolaldehyde (3) was isolated as a white powder (623 mg, 55\% yield). 
${ }^{1} \mathrm{H}$ NMR (400 MHz; $\mathrm{CDCl}_{3}$ ) : $\delta_{\mathrm{H}}$, ppm 9.44 (s, 1H, $\mathrm{H}_{\mathrm{CHO}}$ ), 7.77-7.75 (m, 2H, $\mathrm{H}_{1,3}$ ), 7.64-7.62 $\left(\mathrm{m}, 2 \mathrm{H}, \mathrm{H}_{4}, 5\right), 7.41-7.35\left(\mathrm{~m}, 3 \mathrm{H}, \mathrm{H}_{6,7,8}\right), 2.03-1.99\left(\mathrm{~m}, 4 \mathrm{H}, \mathrm{H}_{\mathrm{a}}\right), 1.13-1.04\left(\mathrm{~m}, 4 \mathrm{H}, \mathrm{H}_{\mathrm{c}}\right), 0.67$ $\left(\mathrm{t}, J=7.2 \mathrm{~Hz}, 6 \mathrm{H}, \mathrm{H}_{\mathrm{d}}\right), 0.60-0.52\left(\mathrm{~m}, 4 \mathrm{H}, \mathrm{H}_{\mathrm{b}}\right) .{ }^{13} \mathrm{C}\left\{{ }^{1} \mathrm{H}\right\} \mathrm{NMR}\left(400 \mathrm{MHz}, \mathrm{CD}_{2} \mathrm{Cl}_{2}, \mathrm{ppm}\right): \delta=$ 176.6 (CHO), 151.5, 151.1, 144.6, 139.7, 132.5, 128.5, 127.9, 127.1, 123.1, 120.5, 119.9, 117.2, 96.3, 88.8, 55.2, 39.9, 25.9, 23.0, 13.5. HRMS-ESI for $\mathrm{C}_{24} \mathrm{H}_{27} \mathrm{O}: \mathrm{m} / \mathrm{z}=331.2060[\mathrm{M}]^{+}$ (calcd: 331.20619); for $\mathrm{C}_{24} \mathrm{H}_{26} \mathrm{O}: \mathrm{m} / \mathrm{z}=330.1990$ [M] ${ }^{+}$(calcd: 330.19837).

Meso-alkynyl fluorenyl porphyrin (TAFlP): In a two-neck flask, a mixture of 9,9-dibutylfluorenyl-2-propiolaldehyde (3) (300 mg, $0.91 \mathrm{mmol}, 1$ equiv) and distilled pyrrole (0.06 mL, $0.91 \mathrm{mmol}, 1$ equiv) were dissolved in dried chloroform $(60 \mathrm{~mL})$ under argon. After degassing the mixture with argon bubbling for $30 \mathrm{~min}, \mathrm{BF}_{3} . \mathrm{OEt}_{2}(0.02 \mathrm{~mL}, 0.16 \mathrm{mmol}, 0.25$ equiv) was injected and the reaction was stirred in dark for $1 \mathrm{~h}$ under $\operatorname{argon}$ at $-30{ }^{\circ} \mathrm{C}$. Then $p$ chloranil (315 mg, $1.28 \mathrm{mmol}, 0.75$ equiv) was added as oxidant, and the reaction was continued at room temperature. for another hour. At last, $\mathrm{NEt}_{3}(2 \mathrm{~mL})$ was injected, and the reaction medium was kept stirring for several minutes. After evaporation of the volatiles, purification of the residual solid was done by silica chromatography using THF/heptane (1:10) mixtures as eluents. TAFIP was collected as green powder (10 $\mathrm{mg}, 3 \%$ yield). ${ }^{1} \mathrm{H}$ NMR (400 MHz; $\mathrm{CDCl}_{3}$ ) : $\delta_{\mathrm{H}}$, ppm 9.69 (s, 8H, $\mathrm{H}_{\beta \text {-pyrrolic }}$ ), $8.11\left(\mathrm{~d}, 8 \mathrm{H}, J=10.5 \mathrm{~Hz}, \mathrm{H}_{1,3}\right.$ ), $7.96\left(\mathrm{~d}, 4 \mathrm{H}, J=7.6 \mathrm{~Hz}, \mathrm{H}_{4}\right), 7.88-7.85\left(\mathrm{~m}, 4 \mathrm{H}, \mathrm{H}_{5}\right), 7.51-7.43\left(\mathrm{~m}, 12 \mathrm{H}, \mathrm{H}_{6,7,8}\right), 2.30-2.15$ (m, $\left.16 \mathrm{H}, \mathrm{H}_{\mathrm{a}}\right), 1.25-1.17\left(\mathrm{~m}, 16 \mathrm{H}, \mathrm{H}_{\mathrm{c}}\right), 0.78\left(\mathrm{t}, 24 \mathrm{H}, J=7.3 \mathrm{~Hz} \mathrm{\textrm {H } _ { \mathrm { d } }}\right), 0.75-0.62\left(\mathrm{~m}, 16 \mathrm{H}, \mathrm{H}_{\mathrm{b}}\right),-1.36$ (s, 2H, NH). ${ }^{13} \mathrm{C}\left\{{ }^{1} \mathrm{H}\right\} \mathrm{NMR}\left(400 \mathrm{MHz}, \mathrm{CD}_{2} \mathrm{Cl}_{2}, \mathrm{ppm}\right): \delta=151.3,151.2,142.4,140.5,131.1$, 127.9, 127.0, 126.1, 123.1, 121.7, 120.1, 103.1, 55.4, 40.3, 29.7, 26.2, 23.2, 13.7. UV-vis $\left(\lambda_{\max }, \mathrm{CH}_{2} \mathrm{Cl}_{2}, \mathrm{~nm}\right): 319,479,661,748$. HRMS-ESI for $\mathrm{C}_{112} \mathrm{H}_{111} \mathrm{~N}_{4}: \mathrm{m} / \mathrm{z}=1511.8797[\mathrm{M}+\mathrm{H}]^{+}$ (calcd: 1511.88033).

\section{CONCLUSIONS}

We have successfully synthesized and characterized the new meso tetrafluorenylethynylporphyrin derivative (TAFIP). Linear optical measurements reveal better conjugation between the porphyrin core and the peripheral fluorenyl-containing antennae, than in the TFP-Bu core. This results from the presence of an yne linkage at the meso positions which allows more planar conformations. We now look forward to use similar central platforms for the design of new families of dendrimers. We hope that the extended and 
more conjugated $\pi$-manifold, besides providing a desirable red-shift for theranostic and high fluorescence for imaging will also enhance the 2PA of the central core allowing for more efficient photosensitizers to be accessed. For the moment, extensive studies of the NLO properties of TAFIP are in progress to verify this point.

\section{Acknowledgments}

The authors acknowledge China Scholarship Council (CSC) for PhD funding (XZ). The authors acknowledge Dr Frédéric PAUL, Dr Olivier MONGIN for fruitful discussion and exchange. This project was partially supported by the departmental committees CD35 and CD85 of the "Ligue contre le Cancer du Grand-Ouest".

\section{REFERENCES}

[1] a) K. Szaciłowski, W. Macyk, A. Drzewiecka-Matuszek, M. Brindell and G. Stochel, Chem. Rev., 2005, 105, 2647; b) Du, B.; Fortin, D.; Harvey, P. D. Inorg. Chem. 2011, 50, 11493; c) Li, B.; Xu, X.; Sun, M. et al., Macromolecules 2006, 39, 456; d) Harth, E. M.; Hecht, S.; Helms, B.; Malmstrom, E. E.; Fréchet, J. M.; Hawker, C. J. J. Am. Chem. Soc. 2002, 124, 3926; e) Sun, M.; Bo, Z. J. Polym. Sci., Part A: Polym. Chem. 2007, 45, 111; f) Kozaki, M.; Morita, S.; Suzuki, S.; Okada, K. J. Org. Chem., 2012, 77, 9447; g) Drouet, S.; Paul-Roth, C.; Simonneaux, G. Tetrahedron 2009, 65, 2975. h) Drouet, S.; Paul-Roth, C. O. Tetrahedron 2009, 65, 10693; i) C. Paul-Roth, G. Williams, J. Letessier and G. Simonneaux Tetrahedron Lett. 2007, 48, 4317; j) Yao, D.; Hugues, V. Blanchard-Desce, M.; Mongin, O.; Paul-Roth, C. O.; Paul, F.; New J. Chem., 2015, 39, 7730; k) Frampton, M. J.; Magennis, S. W.; Pillow, J. N. G.; Burn, P. L.; Samuel, I. D. W. J. Mater. Chem., 2003, 13, 235; 1) D. Yao, X. Zhang, O. Mongin, F. Paul and C. O. Paul-Roth, Chem. Eur. J. 2016, 22, 5583; m) D. Yao, X. Zhang, A. Triadon, N. Richy, O. Mongin, M. Blanchard-Desce, F. Paul and C. O. Paul-Roth, Chem. Eur. J. 2017, 23, 2635.

[2] a) R. W. Wagner, J. S. Lindsey, J. Am. Chem. Soc., 1994, 116, 9759; b) H. L. Anderson, Inorg. Chem., 1994, 33, 972.

[3] D. P. Arnold, L. J. Nitschinsk, Tetrahedron, 1992, 48, 8781.

[4] S. M. LeCours, H. W. Guan, S. G. DiMagno, C. H. Wang, M. J. Therien, J. Am. Chem. Soc., 1996, 118, 1497. 
[5] H. L. Anderson, S. J. Martin, D. D. C. Bradley, Angew. Chem. Int. Ed. Engl., 1994, 33, 655.

[6] R. W. Wagner, T. E. Johnson, F. Li, I. S. Lindsey, J. Org. Chem., 1995, 60, 5266.

[7] V. S. Y. Lin, S. G. DiMagno, M. J. Therien, Science, 1994, 264, 1105.

[8] H. L. Anderson, J. K. M. Sanders, Angew. Chem. Int. Ed. Engl., 1990, 29, 1400.

[9] H. L. Anderson, J. K. M. Sanders, J. Chem. Soc. Chem. Commun., 1992, 946.

[10] L. G. Mackay, H. L. Anderson, J. K. M. Sanders, J. Chem. Soc. Chem. Commun., 1992, 43.

[11] H. L. Anderson, Tetrahedron Lett., 1992, 33, 1101.

[12] L. R. Milgrom, G. Yahioglu, Tetrahedron Lett., 1995, 36, 9061.

[13] L. R. Milgrom, G. Yahioglu, Tetrahedron Lett., 1996, 37, 4069.

[14] L. R. Milgrom, G. Yahioglu, Adv. Mater., 1997, 9, 313.

[15] F. Z. Henari, W. J. Blau, L. R. Milgrom. G. Yahioglu, D. Phillips, J. A. Lacey, Chem. Phys. Lett., 1997, 267, 229.

[16] G. Proess, D. Pankert, L. Hevesi, Tetrahedron Lett., 1992, 33, 269.

[17] A. Bugarin, B. T. Connell, Tetrahedron Lett., 2015, 23, 3285.

[18] J. Lacey, D. Philipps, L. R. Milgrom, G. Yahioglu and R. D. Rees, Photochem. Photobiol. Sci. 1998, 67, 97.

[19] P. K. Goldberg, T. J. Pundsack and K. E. Splan, J. Phys. Chem. A 2011, 115, 10452.

[20] Perrin, D. D.; Armarego, W. L. F. Purification of Laboratory Chemicals, 3rd edn., Pergamon Press, Oxford, 1988. 
